Abordagem 


\section{O Descompromisso do Estado e a Ascensão da Cultura de Alto Consumo}

\section{JOSÉ EDUARDO MARTDNS*}

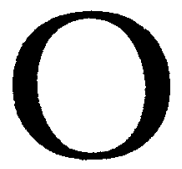

tratamento da produção cultural no Brasil obedece, em sua trajetória, a preferências circunstanciais.

Seria impossivel buscar-se uma homogeneidade no todo cultural do país. Temporariamente privilegia-se determinado segmento, em detrimento de outros, atendendo-se a vários interesses e à maior proximidade do poder com certas áreas da cultura. $\grave{A}$ qualidade da produção antepóem-se, desde o periodo do Império, passando-se pelos governos republicanos, os tentáculos dos agentes culturais isolados que eventualmente poderiam ser artistas.

Mais precisamente as últimas décadas assistiram ao progressivo deteriorar dos valores culturais que persistiam pela tradiçăo, inversamente à ascensáo do marketing cultural privado atento ao lucro e que orienta o seu curso dependendo de interesses múltiplos. Essa postura teria ressonâncias claras na própria intermediação cultural do Estado historicamente mantendo Institutos que, apesar das benesses detectáveis a grupos ou indivíduos, atendiam aos apelos do talento emergente, incentivando-o, propiciando a possibilidade de que este persistisse no meio cultural. A qualidade individual, aceita pela comunidade graças à autoconfiança gerada em parte pelo patrocínio do Estado, passava a produzir, a insistir e sobremaneira a crescer. Talento e ausência tiveram na história da cultura artística brasileira a guarida do Estado, o primeiro desenvolvendo a sua especificidade e muitas vezes ultrapassando as fronteiras do país, o segundo alojando-se na ratificaçáo protetora do desempenho burocrático e, freqüentemente, atuando com ponderação.

Se considerado for $o$ aspecto proteçáo, desde a Idade Média o poder propiciava a produção artística, sendo que nobres e hierárquicos elevados amparavam em seus muros o que era realizado pelo criador $e$

* Jose Eduardo Martinś é pianista e professor do Departamento de Música da Escola de Comunicaçóes e Artes da USP. 
desempenhado pelos intérpretes. Músicos, escritores, pintores alojavam-se no Poder e mesmo em náo se sentindo manipulados, o eram no dirigismo e menos na essência ou idéia inicial que um criador tem de determinada produçáo. Observou-se em regimes totalitários deste século XX - Alemanha nazista, Brasil no Estado Novo - a música como um todo servindo à propagaçáo ideológica. Mais presentemente vê-se o protecionismo Estatal abrigando nos EUA, Japão, Europa como um todo, Uniáo Soviética e Cuba a criaçáo, dando-lhe apoio e incentivo. Se nos países de regime comunista essa proteçáo era ou é total, nos países de regime capitalista, Estado e iniciativa privada unem-se tantas vezes para fomentar a produção artística, sabedores de que o retorno financeiro em determindados segmentos da cultura torna-se praticamente impossível. Institutos e fundaçóes persistem nesses países capitalistas apesar das mudanças dos governos.

No Brasil, a atuaçáo do Estado, que revertia em claro posicionamento de prestígio político àqueles que exerciam o poder, podia-se sentir desde o amparo ou estímulo nos vários campos da atividade cultural, cinema, música, artes plásticas, teatro. Distorçóes na proporcionalidade das destinações de verbas culturais sempre existiram no país e fazem parte de uma outra crônica "cultura", a do tráfico de influências. Mas, apesar dos meandros por vezes obscuros, havia um intermediaçáo satisfatória. A tudo uma imprensa descompromissada com o lucro, entenda-se idealisticamente amadorística, dava vazão ao produzido artisticamente, enfatizando concertos, exposiçōes, a ação teatral e a exibição de filmes, muitos destes sem a grande acolhida do público, mas que granjeavam para o Brasil uma notoriedade quanto à direção. Jovens ou consagrados praticantes de arte podiam, inclusive, ter espaços iguais na mídia do eixo Rio-São Paulo. Na medida em que a ascensão do agente "cultural" se tornou presente em quase todas as áreas da atividade artística, assistiu-se ao lento eclipsar das manifestações e divulgações espontâneas por parte do Estado e da mídia, respectivamente.

Várias são as causas de toda essa situação que hoje se apresenta em impasse. Primeiramente o agente "cultural" entende a "arte" unicamente como fonte de lucro. A ele pouco importa a qualidade mas sim qualquer mitificado e a divulgaçáo a mais ampla em setores os mais abrangentes.

O perfil desse empresário ou agente é quase que totalmente tipificado. A cultura é encarada como uma mercadoria. Anteriormente, esse agenciador poderia ter trabalhado na difusão de um sabonete, ou refrigerante, ou palha de aço, ou trator ou absorvente feminino. $\mathrm{Na}$ iniciativa privada eles superproliferam, mudando de empresas e 
$O$ agenciador basicamente um despreparado culturalmente, mas um executivo de "sucesso" d frente de

departamentos definidos de empresas privades.

basicamente de produtos a serem colocados no mercado. Quando penetra na área cultural, sem a sensibilidade própria dos vários segmentos artísticos, o agente se movimenta paquidermicamente; quase tudo destruindo, na necessidade imperiosa de subsistir . proporcionando o desiderato final, o lucro. Se a área "erudita" é notadamente - graças a vícios que se perpetuam - frágil em termos de público, no que se refere a espetáculos, concertos, exibiçōes de exposiçáo de artistas brasileiros quando em ação qualitativa, investe o agente na área do alto consumo, da alta absorçáo e rotatividade.

Beneficia o quantitativo, desprezando qualquer participaçāo qualitativa. Tendo-se como exemplo as gravadoras de discos, fitas e CDs, verifica-se que a própria MPB ressente-se da avalanche sertaneja e dos rocks importados ou readaptados no Brasil, em conteúdos sempre piorados (1).

O agenciador é basicamente um despreparado culturalmente, mas um executivo de "sucesso" à frente de departamentos definidos de empresas privadas. Ele estará atento quando voltado à cultura, preferencialmente a filmes de comunicadores superconhecidos ou de erotismo banal; ao teatro descartável compreendendo-o "meno male" ; à promoção através de leilóes e exposiçóes dirigidas de "artistas plásticos" que aceitam a manipulaçáo; aos shows de nomes consagrados de segmento específico " musical". Neste último, servindo aos interesses das grandes empresas, 0 agenciador busca promover os nomes mais ventilados da música de alta rotatividade, não só através das gravaçóes, como na divulgação e futura colocação dessas no mercado, encharcando o ouvinte e futuro consumidor. Exemplo vivo é o proporcionado por programas do tipo Fantástico, que exibem preferencialmente aquilo que está atrelado a lançamentos discográficos e a shows manipuladores. A divulgaçáo desses programas televisivos enfatiza os "clips dinâmicos" que representariam um outro universo "cultural", grande parte norte-americanos ou realizados mais pobremente no Brasil, mas seguindo a orientaçáo repetitiva. $O$ comprometimento se estende aos órgáos de imprensa de maior circulação no eixo Rio-São Paulo e muitos deles já optaram prioritariamente pela qualidade estranha, acompanhando o modismo da música de alto consumo, aproximando-se, neste aspecto, das rádios e TVs. Uma consulta a mais elementar aos arquivos das empresas responsáveis por esses jornais e revistas torna patente a degradação cultural no que se refere ao que era divulgado cotidianamente há vinte anos, com o que se apresenta atualmente, evidenciando por outro lado, que a música erudita praticada por brasileiros ficou basicamente

(l) Tupã Gomes Correa penetra nesse universo distorcido, conceituando e exibindo estanísticas em: Rock, nos passos da moda: media, consumo $x$ mercado. Campinas, Papirus, 1984; e Morcado da Música - disco e cilienafato. São Paulo, Expert, 1987. 
marginalizada. Poder-se-ia alegar que o mesmo ocorreria em outros países capitalistas. Contudo, há espaços cotidianos para a música erudita, para a cultura como um todo. Observa-se que o modelo capitalista brasileiro, ratificadamente nomeado como selvagem, melhor ficaria definido pela palavra irracional.

Acentuadamente se verifica a diminuiçăo de espaços para a cultura musical denominada erudita. Se uma parcela da imprensa foi mencionada, é pelo fato de que representava o que de mais significativo existia em termos culturais nos grandes centros culturais brasileiros. Contudo, frise-se, na década de 1950, com uma populaçāo em torno de dois milhōes de habitantes, São Paulo possuía críticos em jornais com O Estado de Sao Paulo, Folha da Manhä, Diário de São Paulo, Diário da Noite, A Gazeta, Correio Paulistano, $O$ Tempo, Giornale degli itagliani, Fanfulla, Jornal Alemão. Artistas renomados ou jovens talentos recebiam, após apresentação, a partir do dia seguinte, críticas em todos esses jornais. Essa postura resultava em estímulo para os que iniciavam; ratificaçăo para os que operavam; informaçăo e comparatividade para a comunidade. Percebe-se hoje a redução drástica dos espaços espontâneos: Organizaçóes como a Sociedade de Cultura Artística ou o Mozarteum Brasileiro, recebendo o patrocínio de grandes empresas, trazem para o Brasil importantes conjuntos ou solistas e têm, aí sim, ampla cobertura da mídia.

No âmbito da música de alto consumo, os agentes culturais, atraindo as grandes empresas, carregam consigo, sem a prévia avaliação, a mídia em seu todo. $O$ jogo de interesses fica ratificado no último elo antes do evento, os meios de comunicaçáo completamente comprometidos.

O insistir no agente "cultural" é conseqüencia lógica do que ocorreria mais recentemente na ascensáo de um Brasil rotulado, agora de Novo. Como se náo bastasse a essência do nome dó país, unicamente. Para a cultura em geral, para a música erudita especificamente, essa ascensáo foi um desastre. Gilberto Mendes já observara o estado precário a que chegou a nossa cultura: "... que vai de mal a pior neste miserável mundo musical em que vivemos no país, principalmente nestes dias" (2). Um exemplo dessa hecatombe foi a desativação da Funarte e da Embrafilme, que, eufemisticamente, insistem os detentores do poder em observar o provável surgimento de nova orientaçăo. A Fundaçăo Nacional da Arte foi importantíssima em todas as suas áreas de atuaçáo. No setor especificamente musical, teve na última década a Direção descompromissada de um Edino Krieger. Nos mais

(2) Gilberto Méndes, 'Os caminhos da nóva música' In:- O Estado de Săo Paulo. Cultrura. Săo Paulo, ano VII; n. 513; 02.06.90.; p. 6. 
longínquos rincōes deste país, a ação da Rede Funarte se fazia sentir, através de palestras, recitais e concertos, cursos de extensáo ou especialização, seminários, colóquios e reciclagens, havendo sempre a obrigatoriedade de determinada parte das apresentaçōes estar destinada à música brasileira. A Funarte fomentava a música coral, as bandas espalhadas pelo Brasil, estimulava a formaçáo de orquestras-escolas, promovia concursos, lançava jovens talentos, prestigiava os que professavam a carreira musical, integrava jovens e artistas ventilados. Editava partituras, livros e catálogos, lançava discos onde a preservaçáo da Memória se fazia estabelecida, tudo com verbas reduzidíssimas. Quanto às gravaçóes, cujas tiragens eram pequenas neste país culturalmente à deriva, o Pró-Memus da Funarte foi responsável pela perpetuação de tantas obras conservadas precariamente em manuscritos ou editadas em quantidade pequena. Alberto Nepomuceno, Leopoldo Miguez, Henrique Oswald, Carlos Gomes, Villa-Lobos, Francisco Mignone, Camargo Guarnieri, entre tantos, tiveram raridades divulgadas. Essas propiciaram, sob outra égide, o estímulo e tantos não foram os intérpretes que sentiram que o "multum in minimo" da Funarte era para valer, mesmo que tivessem de guardar anos em fila de espera, a fim de gravarem determinada obra. A consulta ao catálogo da discografia da Funarte é um atestado irrefutável. Quantidades pequenas, alguns poucos milhares de discos eram distribuídos a preços irrisórios em função cultural que compete ao Estado - lembrem-se as partituras, livros e discos editados na Hungria, Polônia e Uniāo Soviética - em todo território nacional. Ínfima parcela se considerada for uma comparaçáo com o lixo

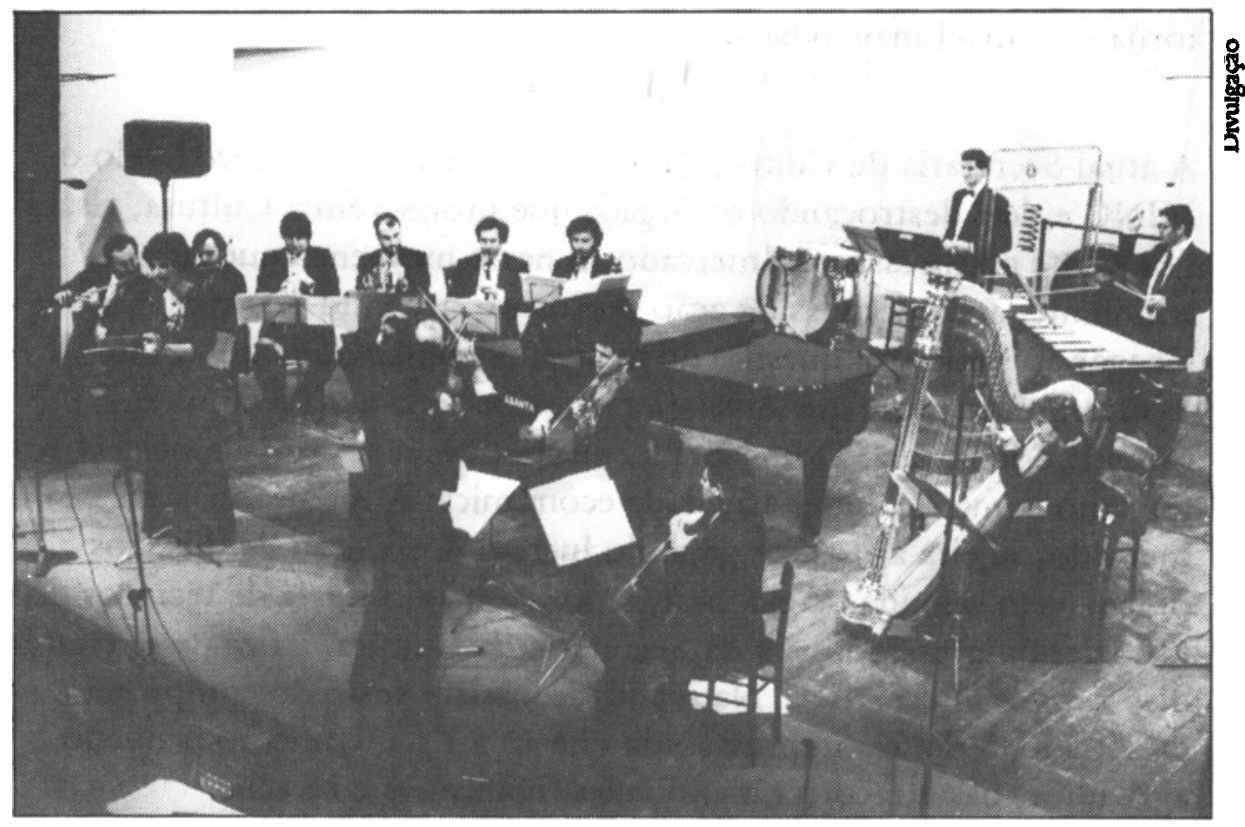

O. grupo italiăno Bruno Maderna, répertoriando a música do século 20, teria acesso a fururas apresentaçóes no Brasil? 
descartável das grandes gravádoras pressionando o modismo altamente divulgado, que meses após desaparecerá ou estará jogado em sebos de discos às toneladas. Fundaçăo, produtores de cultura musical entendam-se aqueles que realizam música - aceitavam "cachês" rebaixados, mas plenamente dignificadores, pois recebidos após uma " missão" para a comunidade.

A extinção da Funarte e consequentemente do Pró-Mèmus apresenta-se como uma verdadeira catástrofe na esfera musical. Sem ela, uma quantidade enorme de cidades brasileiras deixará de ter contato direto com a açáo musical específica, as pesquisas de campo perderáo o incentivo, a preservaçáo da Memória tornar-se-á totalmente comprometida e desestimulada, as catalogaçōes de autores da maior importância ficaráo interrompidas. A curto prazo, a desativaçăo da Funarte secará, no próprio desabrochar, talentos que se perderáo ou que se destinarảo a áreas não vocacionadas.

A ascensão do "Brasil Novo", priorizando o econômico-recessivo tem em seu parto quantidade de milhares de poupanças mutiladas, disfarçando o prometido enxugamento da máquina do Estado, suprimindo de partida a Embrafilme, a Funarte e outros que possivelmente maiores benefícios trazem à coletividade naquilo que concerne à preservaçáo da identidade. Se Cultura foi tratada de maneira superficial em discurso de posse da Ministra Esther de Figueiredo Ferraz à frente do MEC, ou insubstancialmente no de outro Ministro, Celso Furtado - competente em outra área -, a desativaçáo do MINC e a criaçáo de uma Secretaria de Cultura torna-se o nível mais rebaixado de nossa cultura.

A atual Secretaria de Cultura do Governo Federal, em sucedendo o MINC e dele destroçando os órgáos que promovem a Cultura, visará doravante a expressão do mercado. É nesse momento que surge triunfante, após décadas de açáo corrosiva, o agente "cultural". Chegar ao poder foi questáo de tempo. A mentalidade do agente "cultural" privado, que nivelara por baixo toda a ação cultural, ascende e se instala. Doravante a cultura deverá ser tratada pelo novo governo como qualquer atividade econômica. A intenção é a de mercado, sujeita a riscos e gerando lucros. A extinção de diversos órgãos vem seguida de elaboraçáo por comissáo mista de técnicos do Ministério da Economia e da Secretaria da Cultura, a fim de se criarem dispositivos alternativos. $\mathrm{Na}$ realidade, assiste-se ao descompromisso do Estado, à fictícia impressáo de que ao artista, como ao pequeno agricultor, basta recorrer a entidades financeiras e recolher empréstimos com juros "menores" e, após peça teatral, ou orquestra, ou exposição de arte, ou filme elaborado e exibido diante da total 
Na realidade,

assiste-se ao descompromisso do Estado, à fictícia impressão de que ao artista, como ao pequeno agricultor, basta recorrer a entidades

financeiras $e$ recolher empréstimos

nebulosidade de sucesso de bilheteria, fica o fantasma da devoluçáo ao agente financeiro dos empréstimos devidamente acrescidos. Essa é a mentalidade distorcida da cultura própria do irracionalismo.

Alguns pontos merecem um pormenorizar nessa busca à fonte financeira. Três são significativos. Um primeiro, no qual fatalmente os projetos de fácil certeza de sucesso financeiro, como filmes de comunicadores, peças teatrais e shows descartáveis terão acesso direto, pois torna-se nítido o retorno e a impulsáo dessa baixa qualidade será estimulada pela imprensa, rádio e TV comprometidas. Os elos se ligam e o público inteiramente manipulado dirigir-se-á aos espetáculos e exibiçóes. Em um segundo ponto estarão os agentes com projetos "fantasmas", como ocorre habitualmente em áreas as mais diversas deste Brasil, projetos de grandes ou médios empreendimentos que, após verbas recebidas, desaparecem e que periodicamente proliferam nos noticiários dos jornais. Os juros menores serăo estímulo à manipulaçáo fraudulenta. Em terceiro lugar, desprotegido, esmagado pelo peso do absurdo, estará o idealista que busca recursos para o filme experimental, para o ballet de vanguarda, para o Festival de Música Contemporânea, para a formaçáo de uma orquestra. A esse segmento, sem lastro que comprove o futuro retorno, restará o bolsáo da resistência, essa maneira dignificante mas desencorajadora de se tentar fazer arte no Brasil. Sempre haverá a esperança de que determinadas Secretarias de Governos Estaduais ou Municipais náo se contaminem. Como náo se entusiasmar com a açáo cultural de pequenos recursos, mas abrangente, da Secretaria de Cultura de Santos, plena de trabalho, ação e eventos?

Nesse quadro fantasmagórico, sempre o hábil agente "cultural" levará os empréstimos, fazendo com que as grandes firmas se associem aos empreendimentos, pouco importando a qualidade, contanto que o retorno seja líquido em termos promocionais. Dois exemplos sáo típicos, um primeiro ligado às corridas de Fórmula-l, onde a qualidade insofismável de nossos corredores sáo provas de emprego da propaganda que se poderia entender e da ampla divulgaçáo nos meios de comunicação. Tal náo ocorre com o tênis brasileiro. Não é preciso salientar que este está em estágio de mediocridade. Os nossos "melhores" jogadores, quando passam de uma primeira rodada fora do país, sucumbem em uma segunda. As colocaçōes no "ranking" mundial são a evidência da categoria inferior dos tenistas brasileiros. Contudo, quantidades de torneios de baixa qualidade com jogadores internacionais igualmente não categorizados são insistentemente realizados no Brasil. Algumas das maiores empresas multinacionais patrocinam esses torneios e os principais jornais dedicam páginas inteiras, enganando o leitor nos elogios à avalanche de jogos que năo 
resistem a qualquer crítica capacitada dos que realmente pertencem ao tênis de primeira linha. Que a iniciativa privada e a mídia sabem disso, é certo, mas atrás de tudo há os agentes ávidos em retornos, mal se importando com as conseqüências de todo esse nivelamento absurdo. As firmas, apostando na mentira, criam no consumidor a ilusáo da verdade, resultando num profundo embuste. A mídia ratifica o óbvio.

Quanto à música, o mesmo se verifica. Diariamente o grande consumo é ventilado e exaltado. A música erudita professada por compositores e intérpretes brasileiros vê gradativamente os espaços se esvaírem. Interesses inconfessáveis se mostrariam na explicação do que ocorre.

A busca ao retorno financeiro e o descompromisso do Estado, que doravante nortearăo a cultura brasileira, têm nas palavras da atriz e empresária Ruth Escobar motivos para reflexăo: "Ou se trata de um plano sórdido e sinistro para acabar com a cultura ou é ignorância mesmo". É possível que sejam os dois .

O que restará? Os bolsőes da resistência cultural. O teatro experimental e os Festivais de Música Contemporânea, desprotegidos mas acreditando. Os textos culturais destinados a órgáos da imprensa que também tiveram espaços reduzidos, buscaráo os bolsőes da resistência em Suplementos de Cultura, como o do $O$ Estado de Säo Paulo, apesar de ter tido espaço sensivelmente reduzido nos últimos tempos, e nas revistas especializadas que subsistem, pois há uima parcela que pensa, apesar dos agentes "culturais" . Sob outro aspecto, há sempre a nostálgica mas enriquecedora possibilidade de se exilarem textos e apresentaçóes em países outros, à espera de que o que ocorre possa, talvez, se transformar. 